Old Dominion University

ODU Digital Commons

1983

\title{
Transport and Fate of River Discharge on the Continental Shelf of the Southeastern United States
}

\author{
J. O. Blanton \\ L. P. Atkinson \\ latkinso@odu.edu
}

Follow this and additional works at: https://digitalcommons.odu.edu/ccpo_pubs

Part of the Oceanography Commons

\section{Original Publication Citation}

Blanton, J., \& Atkinson, L. (1983). Transport and fate of river discharge on the continental shelf of the southeastern United States. Journal of Geophysical Research: Oceans, 88(C8), 4730-4738. doi:10.1029/ JC088iC08p04730| 


\title{
Transport and Fate of River Discharge on the Continental Shelf of the Southeastern United States
}

\author{
J. O. Blanton and L. P. Atkinson \\ Skidaway Institute of Oceanography, Savannah, Georgia 31406
}

\begin{abstract}
We have analyzed 8 years of wind and salinity data from a frontal zone in a region of the inner continental shelf off the southeastern United States. The changes in low-salinity water stored in the frontal zone have been parameterized by analyzing the monthly rate of change in freshwater content. When the rate of change in freshwater content was negative, we interpreted this as a loss of lowsalinity water from the frontal zone. When this parameter was compared with seasonally averaged alongshore wind stress, the rate of loss was independent of the alongshore wind stress magnitude until threshold of about $0.1 \mathrm{dyne} \mathrm{cm}^{-2}$ was reached. Above the threshold there was a clear relationship between northward alongshore wind stress and rate of loss of freshwater from the inner shelf. Experimental evidence suggests that horizontal currents in the inner-shelf frontal zone have cyclonic shear with increasing depth. When wind stress is northward and offshore, near-surface low-salinity water is transported offshore by Ekman transport while near-bottom high-salinity water is transported shoreward.
\end{abstract}

\section{INTRODUCTION}

Nine major rivers in the southeastern United States (Figure 1) discharge freshwater to the continental shelf of the South Atlantic Bight (SAB). Tidal mixing blends these discharges to form a band of low-salinity water adjacent to the coast [Atkinson et al., 1978; Blanton and Atkinson, 1978; Blanton, 1980]. The low-salinity water overrides ambient shelfwater to form a frontal zone that usually extends 20-30 $\mathrm{km}$ offshore. We define this region as the inner shelf. The frontal zone contains a baroclinic coastal current which transports low salinity water north or south depending upon coastal wind regimes. The offshore pressure gradient induced by low-salinity water turns water to the right within a Rossby radius of about $5 \mathrm{~km}$; thus, in the absence of wind, the coastal current would flow southward. This situation occurs during autumn when coastal currents carry water southward as a consequence of southwestward wind stress [Blanton, 1981]. As a result, lowest-salinity water is found off Florida during autumn [Atkinson et al., this issue], even though there is no known local source of freshwater. During other times of the year, low-salinity water is spread more or less homogeneously along the coast between North Carolina and Georgia.

The dynamics maintaining the frontal zone tend to confine freshwater and dissolved material within the inner $20-30 \mathrm{~km}$ [Blanton, 1981]. This is particularly true when the coastal current flows southward, but when wind stress opposes the tendency for geostrophic flow southward, it is easier presumably to transport low-salinity water offshore. We will describe the transport and fate of the low salinity water under different wind regimes.

Annual heating and cooling, runoff, and wind mixing play interrelated roles that determine the overall stratification on the SAB shelf [Atkinson et al., this issue]. Vertical density gradients are weak in February except adjacent to the coast, but horizontal density gradients across the shelf are quite high. During April, vertical stratification is greater because

Copyright 1983 by the American Geophysical Union.

Paper number 2C1374. 0148-0227/83/002C-1374\$05.00 of increased heat flux and freshwater runoff, particularly in the central SAB, where runoff is concentrated near the coast. We will describe the role of stratification near the coast in advecting low-salinity water offshore from its origin adjacent to the coast.

We show in this paper that the inner shelf of the SAB, particularly off South Carolina and Georgia, is usually a storage zone for freshwater discharged to the coast. However, during spring, the wind regime and increased freshwater runoff decrease the slope of the inner shelf frontal zone allowing enhanced flux of low-salinity water northward and offshore. Thus, physical processes in spring conspire to deplete the freshwater usually stored in the inner shelf frontal zone. Historical runoff and salinity data are used to illustrate the dynamics of the depletive process and its interannual variability.

\section{Historical Discharge Salinity and Wind Stress DATA}

\section{River Discharge}

There are several gauged rivers that can be used to estimate freshwater discharge to the SAB. Approximately $60 \%$ of the gauged runoff is from the Pee Dee, the Savannah, and the Altamaha rivers (Figure 1). Thus we have estimated discharge $\left(Q_{f}\right)$ over approximately $400 \mathrm{~km}$ of coastline by summing the monthly discharge of these three rivers and multiplying by 2 to account for the other gauged plus ungauged flow. (The factor of $1 / 0.6$ accounts only for gauged flow.)

Twenty-year means of coastal runoff (Figure 2) show that a seasonal low of $1000 \mathrm{~m}^{3} \mathrm{~s}^{-1}$ occurs in autumn and a mean maximum of $4000 \mathrm{~m}^{3} \mathrm{~s}^{-1}$ during March. Included in Figure 2 are monthly means for 1980 and 1981 that illustrate abnormally high and low discharge to the inner continental shelf.

\section{Salinity and Freshwater Content on the Inner Shelf}

Areal means for climatological values of inner-shelf salinities for the entire SAB appear correlated with the annual runoff cycle [Atkinson et al., this issue]. To examine correlations in more detail, we have selected the subset of U.S. Atlantic Coastal Lightship data [Day, 1959a, b, 1960, 1963; 


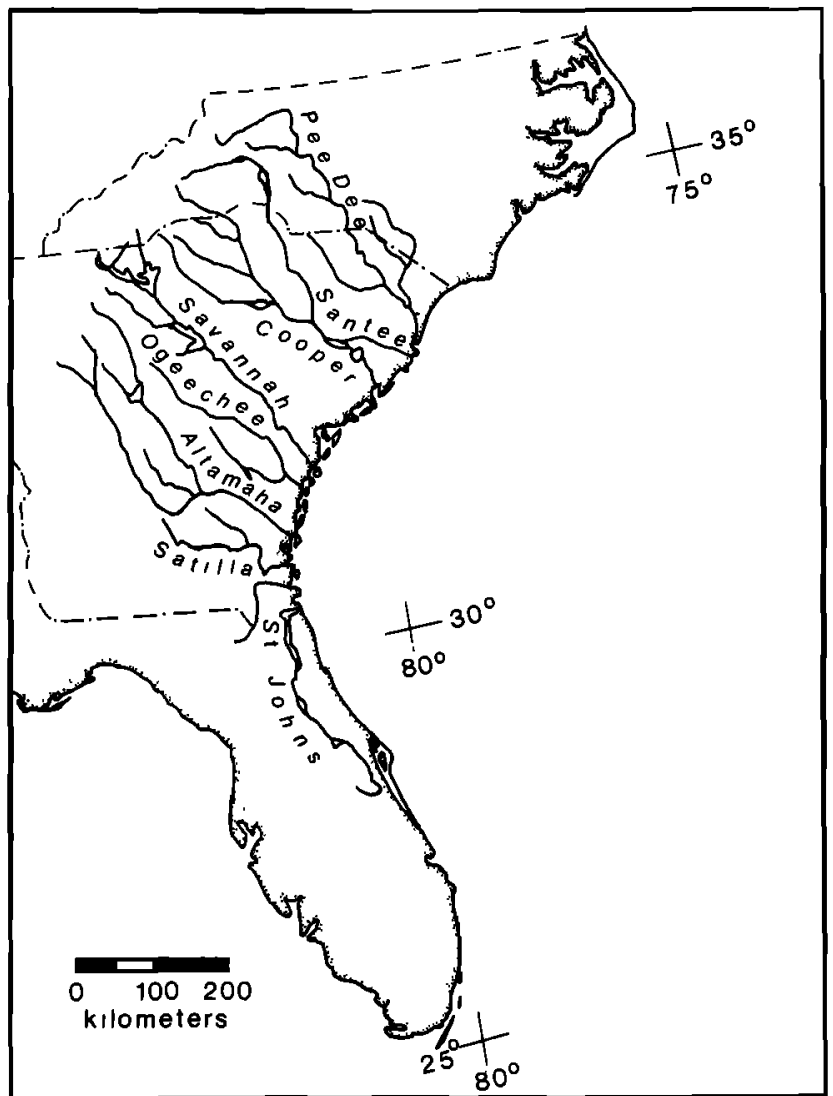

Fig. 1. Map of southeastern United States and major rivers entering the ocean.

Chase, 1964, 1965, 1966, 1967] for the Savannah River Lightship anchored about $15 \mathrm{~km}$ offshore (Figure 3). The lightship was centrally located along the inner shelf, where most river discharge occurs. Over an 8-year period (19571964), surface salinities were taken at a frequency of about one per day. Bottom salinities were obtained less frequently. We obtained a complete set of monthly mean surface salinities, but many of the corresponding mean bottom salinities are questionable because of missing samples. The 8-year monthly means for surface and bottom salinity are compared with the 20-year monthly means of river discharge (Figure 4). Note that peak discharge occurs in March, 1 month before lowest salinities. The inverse correlation between salinity and river discharge is clear.

We investigated the relationship of the salinity minimum to the maximum discharge 1 month previous for each of the 8 years. We assume that salinity $(S)$ is a linear function of depth $(Z)$ between surface and bottom salinity, $S_{S}$ and $S_{D}$, respectively. Using a base salinity, $S_{0}=36 \times 10^{-3}$, and water depth of $D=15 \mathrm{~m}$ at the lightship and $\tilde{S}=(1 / 2)\left(S_{S}+\right.$ $S_{D}$ ), the freshwater fraction $K_{f}$ is

$$
K_{f}=\int_{D}\left(\left(S_{0}-S\right) / S_{0}\right) d z=S_{0}{ }^{-1} D\left(S_{0}-\bar{S}\right)
$$

The units of $K_{f}$ are $\mathrm{m}$ and can be interpreted as $\mathrm{m}^{3} / \mathrm{m}^{2}$ of freshwater.

A plot of maximum monthly discharge versus $K_{f} 1$ month after the maximum (Figure 5) suggests an expected trend where higher discharges $\left(Q_{f}\right)$ reflect generally higher freshwater contents with considerable interannual variability for a

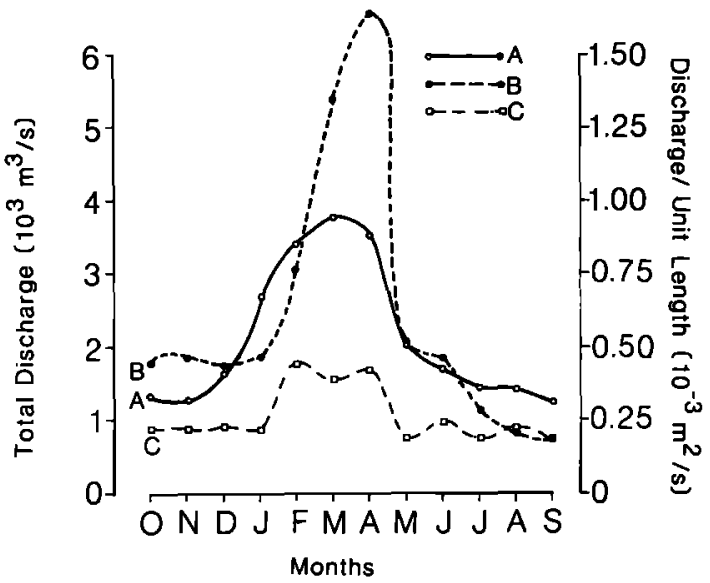

Fig. 2. River discharge to the continental shelf for the coasts of South Carolina and Georgia (see text for details): A, 20-year mean; B, 1980 water year; C, 1981 water year.

given $Q_{f}$. For example, peak discharges of about $5000 \mathrm{~m}^{3} / \mathrm{s}$ occurred in 1958, 1961, and 1962, and maximum $K_{f}$ varied from 1.3 to $2.1 \mathrm{~m}$.

After peak discharge occurs, we expect $K_{f}$ to decrease over time after its maximum value is attained. The rate of decrease is a complex function of transport mixing processes on the inner shelf. A plot of monthly river discharge versus $K_{f}$ for the 8 years (Figure 6) shows a great deal of annual variability. During 1957, river discharge peaked in April at a value substantially lower than the 20-year mean (compare with Figure 2); $K_{f}$, on the other hand, continued to increase through June, even while river discharge was steadily decreasing. In contrast, in 1961, peak river discharge occurred in April at a value 30-40\% higher than the 20-year maximum. In this case the $K_{f}$ curve follows the discharge curve rather closely. Clearly, the transport and fate processes governing the rate of decrease of $K_{f}$ were quite different in these two

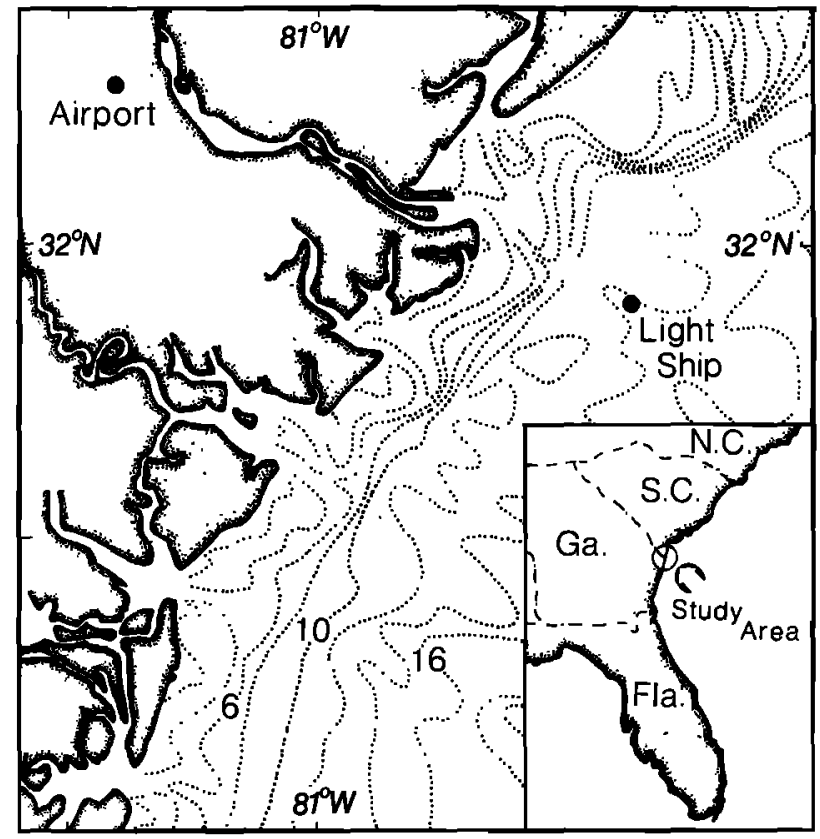

Fig. 3. Detailed map showing multi-inlet coastline and location of the Savannah River Lightship and Savannah Municipal Airport. Bottom contours are in meters. 


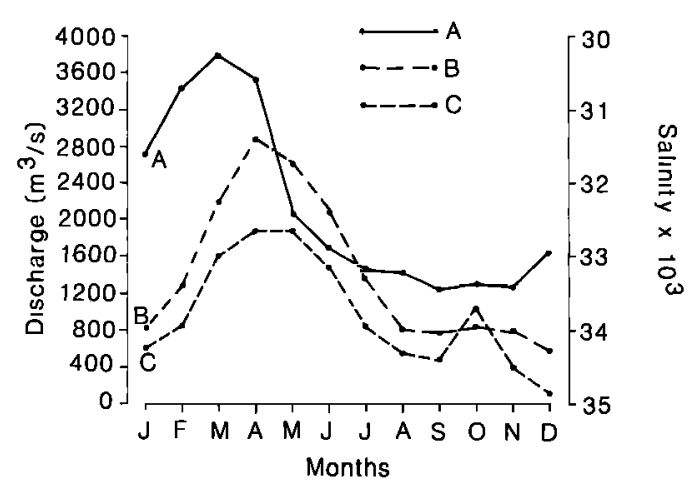

Fig. 4. Relationship of river discharge curve A to salinity off the Georgia coast. Discharge curve is a 20-year mean. Salinity curves (curve B, surface; curve C, bottom) are averages obtained at the Savannah River Lightship from 1957 through 1964 [Day, 1959a, $b$, 1960, 1963; Chase, 1964, 1965, 1966, 1967].

years. We will discuss important factors that will govern the decrease in $K_{f}$ over time $\left(\delta K_{f} / \delta t\right)$. We call the period in spring when $\delta K f \delta t<0$ the 'decay period.'

\section{Wind Stress Impulse}

Wind stress must play a key role in governing the transport and fate of riverine inputs. The wind stress impulse at a point on the ocean surface is simply the integral of the wind stress vector over time. The accumulative effects of wind stress over long time periods can be easily assessed by evaluating curves of impulse. Steeply rising/falling impulse curves based on a given component of wind stress indicate large positive/negative values of stress over the period of rise or fall. A flat curve indicates relatively quiet periods of little stress. These curves give a quick visual impression of the accumulative effects of stress over periods of weeks or months. Moreover, average stress values over a specified period are easily calculated by subtracting the impulse value at the beginning time from the value at end time.

During summer, when the expected maximum in $K_{f}$ decays to low values, the 20-year monthly mean wind stress is usually northeastward [Weber and Blanton, 1980]. This regime is preceded in March and April by a transition period that has great year-to-year variability. While the 20-year monthly means show weak and variable winds, it must be remembered that these means are composed of strong wind events that may increase or decrease a mean value, depending upon the phase of the vectors making up the mean. A preview of Figure 7 will show that the average alongshore stress throughout spring and early summer is northeastward, with significant year-to-year differences in the orthogonal components of the stress vectors that compose the mean. We would expect inner-shelf currents to flow northward with a slight offshore component, except in years when there is enough onshore impulse to overcome the tendency for offshore Ekman transport. We hypothesize that the rate of reduction of freshwater content in the low-salinity band is related, in part, to the strength and variability of wind stress during spring and early summer.

We analyzed daily averages of wind velocity for the years 1957-1964 from the municipal airport in Savannah, Georgia, located about $50 \mathrm{~km}$ from the Savannah River Lightship (Figure 3). These data were converted to daily stress values by the formulas

$$
\begin{aligned}
& \tau_{x}=\rho_{a} C_{D}\left[\left(U^{2}+V^{2}\right)^{1 / 2}\right] U \\
& \tau_{y}=\rho_{a} C_{D}\left[\left(U^{2}+V^{2}\right)^{1 / 2}\right] V
\end{aligned}
$$

where $\tau_{x}$ and $\tau_{y}$ are offshore and alongshore values of stress, respectively; $U$ and $V$ are the corresponding values of the velocity components; $\rho_{a}$ is air density; and $C_{\mathrm{d}}$ is a drag coefficient of $2 \times 10^{-3}$. The daily stress components were converted to components of impulse/unit area by summing the daily values of stress over time beginning with the first of January each year (Figure 7). Thus the components of impulse/unit area, $I_{x}$ and $I_{y}$, can be written

$$
I_{x}=\int_{t} \tau_{x} d t
$$

and

$$
I_{y}=\int_{t} \tau_{y} d t
$$

Plots for each year are easily compared by observing the relative slopes of the impulse components over time scales of 1 or 2 months. These show considerable year-to-year variability in the wind regime off Savannah.

Alongshore impulse curves (Figure 7) usually begin the year with a positive slope, with some intermittent, often strong, reversals. Offshore impulse slopes are also positive and often greater than the alongshore slopes. In general the data suggest that inner-shelf water is given a greater offshore than alongshore impulse between February and April when maximum river discharge occurs and when the buildup of $K_{f}$ occurs. A second common feature during this period is that the offshore impulse slope either greatly diminishes or changes sign. In April, which is the usual time of maximum freshwater content at the Savannah Lightship, the lowsalinity water receives impulses alongshore, but there is a diminishing or even reversing tendency for onshore impulse. A third common feature occurs in August or September when the alongshore impulse slope becomes negative. This indicates the onset of the southwestward wind stress regime of autumn [Weber and Blanton, 1980]. The magnitude of the slopes differs greatly from year to year, suggesting that the variability in the rate of decrease in $K_{f}$ (Figure 5) may be partially accounted for by wind impulses (Figure 7).

We summarize Figures 6 and 7 by tabulating yearly comparisons of the maximum freshwater content on the inner shelf, $K_{f}(\max )$; the freshwater content remaining in

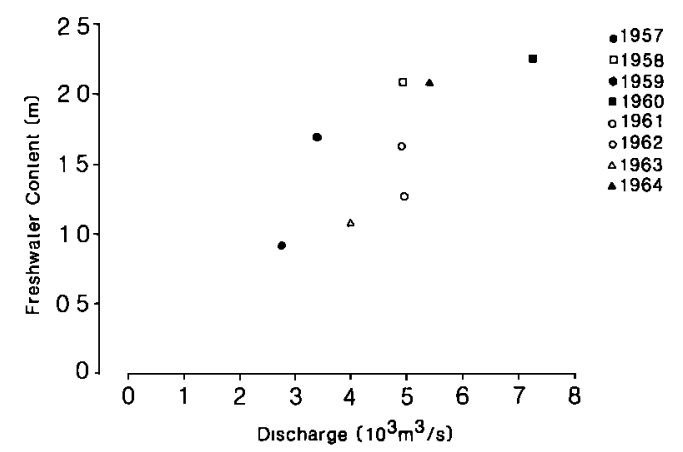

Fig. 5. Maximum river discharge versus freshwater content. Monthly values of freshwater content lag by 1 month the corresponding values of monthly maximum discharge. 

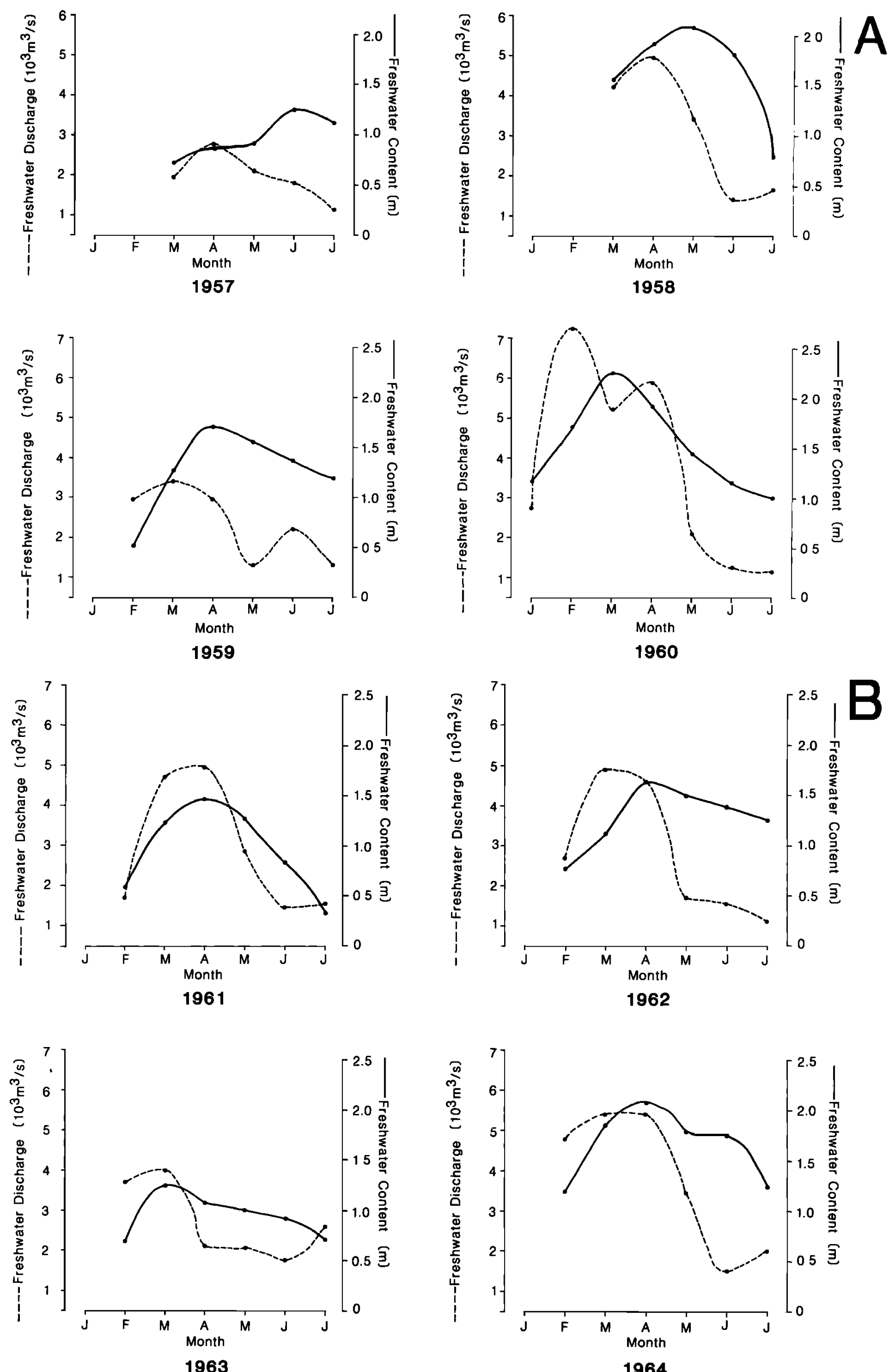

Fig. 6. Plots of river discharge and freshwater content. Plots begin 1 month before maximum (lischarge and end in July: (a) 1957-1960; (b) 1961-1964. 

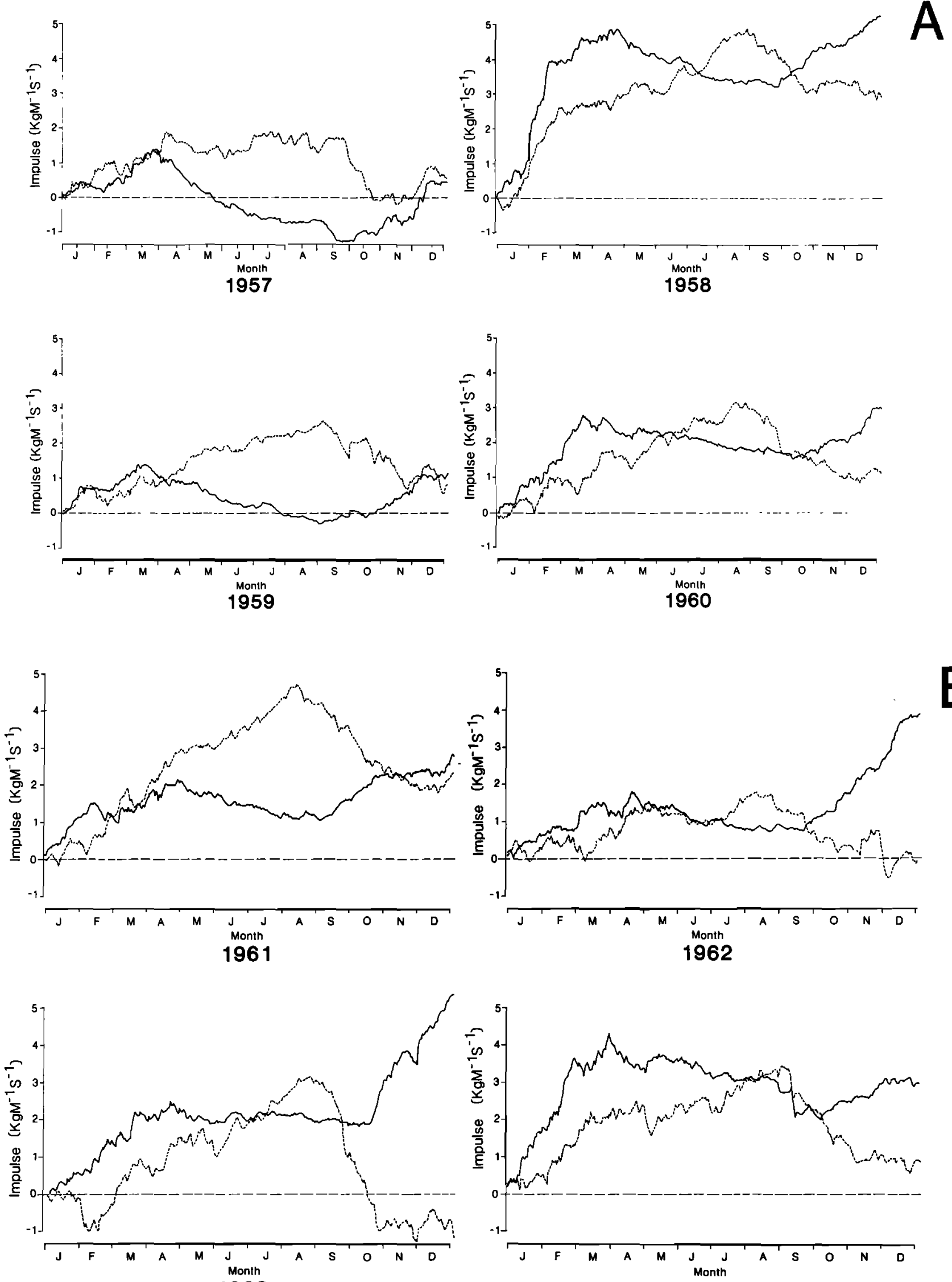

1963

Fig. 7. Alongshore (- - ) and offshore (-) components of impulse per unit area $\left(\mathrm{kg} \mathrm{m}^{-1} \mathrm{~s}^{-1}\right)$ based on daily averages of wind stress at Savannah Municipal Airport (Figure 3). East and north components have been rotated $45^{\circ}$ clockwise: (a) 1957-1960; (b) 1961-1964. 
TABLE 1. Values of Freshwater Content and Average Wind Stress at the Savannah River Lightship

\begin{tabular}{lccccccc}
\hline Year & $\begin{array}{c}K_{\mathrm{f}}(\max ), \\
\mathrm{m}\end{array}$ & $\begin{array}{c}K_{\mathrm{f}}(\mathrm{July}), \\
\mathrm{m}\end{array}$ & $\begin{array}{c}\Delta t, \\
\text { months }\end{array}$ & $\begin{array}{c}\delta K_{\mathrm{f}} / \delta t \\
\left(\times 10^{-8}\right), \\
\mathrm{m} / \mathrm{s}\end{array}$ & $\left.\begin{array}{c}\bar{\delta} \\
\left(\times 1 K_{\mathrm{f}}\right. \\
\mathrm{s}\end{array}\right)$, & $\begin{array}{c}\text { Average Wind } \\
\text { Stress, dyne/cm }\end{array}$ \\
\hline 1957 & 1.24 & 1.12 & 1 & -4.6 & -3.7 & +0.07 & -0.10 \\
1958 & 2.08 & 0.79 & 2 & -24.9 & -12.0 & +0.18 & -0.08 \\
1959 & 1.70 & 1.19 & 3 & -6.6 & -3.9 & +0.11 & -0.10 \\
1960 & 2.25 & 1.00 & 4 & -12.1 & -5.4 & +0.13 & -0.03 \\
1961 & 1.46 & 0.34 & 3 & -14.4 & -9.9 & +0.16 & -0.06 \\
1962 & 1.63 & 1.25 & 3 & -4.9 & -3.0 & -0.01 & -0.05 \\
$1963^{*}$ & 1.25 & 0.71 & 4 & -5.2 & -4.2 & +0.15 & +0.01 \\
1964 & 1.98 & 1.23 & 3 & -9.7 & -4.9 & +0.01 & -0.06 \\
\hline
\end{tabular}

$\tau_{\mathrm{x}}$ is offshore component; $\tau_{\mathrm{y}}$ is alongshore component.

* Questionable averages because bottom salinity data were missing.

$\Delta t \equiv$ time lapse between $K_{\mathrm{f}}(\max )$ and $K_{\mathrm{f}}(\mathrm{July}) \equiv$ decay period.

$\overline{\delta K_{\mathrm{f}}} \equiv\left[K_{\mathrm{f}}(\max )\right]^{-1} \delta K_{\mathrm{f}} / \delta t$.

July, $K_{f}(\mathrm{July}) ;$ and the average offshore and alongshore wind stress, $\tau_{x}$ and $\tau_{y}$, over the period $\Delta_{t}$ (Table 1$)$. We ended the averaging period in July because in August the wind regime often shifts to southwestward wind stress, signaling the onset of autumn as the Bermuda high begins to weaken. Maximum freshwater content $\left(K_{f}(\max )\right)$ varied from 1.2 to $2.2 \mathrm{~m}$, while July values $\left(K_{f}(\mathrm{July})\right)$ ranged from 0.3 to $1.3 \mathrm{~m}$. More importantly, $K_{f}(\max )$ occurred 1 to 4 months before

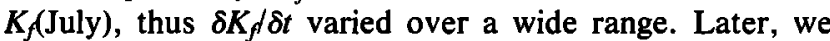
discuss the relationship of decreasing $K_{f}$ to alongshore wind stress.

\section{Discussion}

In the previous section we demonstrated that the maximum freshwater content occurs in the coastal zone in spring. During spring and summer, the wind regime exerts a positive alongshore stress, and freshwater content usually diminishes on the inner shelf. Apparently, wind stress transports the water northeastward with an offshore flow in the surface Ekman layer. Because of the vertical structure of currents in the inner-shelf front during these wind conditions, we can show how the low-salinity water, concentrated in surface layers, is advected offshore and replaced along the bottom by higher-salinity water from the middle shelf. We approach this discussion by first examining the energetics required to vertically mix low-salinity water overriding ambient shelf water. We then examine hodographs of currents during spring conditions when average wind stress is northeastward. Finally, we examine the correlation between decrease in freshwater content and wind stress.

\section{Power Requirements to Vertically Mix Water in the Frontal Zone}

The work required to maintain a mixed state between fluids of different density is

$$
\partial V / \partial t=[(H-h) / 2)] \partial B / \partial t-(B / 2)(\partial h / \partial t)
$$

where $H$ is the depth of a water column that has a density deficit $\rho^{\prime}$ in a surface layer of thickness $h$, and $B=\rho^{\prime} g h$ is the buoyancy force [Fearnhead, 1975]. Following Fearnhead, we neglect the latter term, which represents the initial work required to mix an element of buoyant fluid downward. The remaining term, $(1 / 2)(H-h) \partial B / \partial t$, represents work required to maintain the pycnocline when the upper layer receives a local buoyancy flux. Phillips [1966] shows that the net buoyancy flux across the air-sea interface may be written as

$$
N_{0}=g / \rho_{0}\left[Q_{s}-L E \alpha_{v / c_{p}}-E S\right]
$$

where $Q_{s}=$ net gain of sensible heat by solar radiation or conduction, $L=$ latent heat of evaporation, $E=$ evaporation rate, $S=$ salinity, and $\alpha_{v}=$ volumetric thermal coefficient of expansion; $E S$ represents the rate at which salt mass/unit area is left behind because of evaporation, $E S<0$ represents a dilution rate/unit area to the saltwater mass by freshwater flux. Now, $B=\rho^{\prime} g h$, and $\partial B / \partial t$ is buoyancy force per unit time; thus $\rho^{\prime} N_{0}=\partial B / \partial t$ and

$$
\partial V / \partial t=[(H-h) / 2)] \rho^{\prime} N_{0}
$$

where $N_{0} \approx g / \rho_{0}\left[Q_{s}\left(\alpha_{v} / c_{p}\right)+F\right]$, and $F$ is the freshwater flux in units of $\mathrm{kg} / \mathrm{m}^{2} \mathrm{~s}$.

Freshwater discharges occur over length $L=400 \mathrm{~km}$, and reduced-salinity water is confined to a width of $20-30 \mathrm{~km}$. Mean discharge for 20 years ranges from 1300 to $4000 \mathrm{~m}^{3} / \mathrm{s}$ in September and March, respectively (Figure 2). Table 2 gives estimates of the power required to mix freshwater inputs over extremes represented by the 20-year mean high and low discharges and those represented by the 1980 and 1981 water years.

Approximately $10^{-4}$ to $10^{-3} \mathrm{~W} / \mathrm{m}^{2}$ of power is required to mix the anticipated ranges of freshwater discharges (Table 2). We have included an estimate of the power required to mix solar heat additions with no freshwater discharge for the

TABLE 2. Power Required $\left(\mathrm{W} / \mathrm{m}^{2}\right)$ to Mix Freshwater

\begin{tabular}{|c|c|c|c|c|}
\hline & \multicolumn{2}{|c|}{$\begin{array}{c}\text { 20-year } \\
\text { Mean }\end{array}$} & \multirow{2}{*}{$\begin{array}{l}\text { 1980, } \\
\text { Low }\end{array}$} & \multirow{2}{*}{$\begin{array}{l}\text { 1981, } \\
\text { High }\end{array}$} \\
\hline & Low & High & & \\
\hline $\begin{array}{l}\text { Discharge }\left(10^{3} \mathrm{~m}^{3} / \mathrm{s}^{1}\right) \\
\text { Flux }\left(10^{-4} \mathrm{~kg} / \mathrm{m}^{2} / \mathrm{s}^{1}\right) \\
\partial V / \partial t\left(10^{-4} \mathrm{Wm}^{2}\right)\end{array}$ & $\begin{array}{l}1.3 \\
1.7 \\
2.1\end{array}$ & $\begin{array}{l}4.0 \\
5.1 \\
6.3\end{array}$ & $\begin{array}{l}0.7 \\
0.9 \\
1.1\end{array}$ & $\begin{array}{r}7.0 \\
9.0 \\
11.0\end{array}$ \\
\hline \multicolumn{5}{|c|}{ May maximum of solar heat input [Odum, 1971] } \\
\hline $\begin{array}{l}\text { Solar heat flux }\left(10^{3} \mathrm{kcal} / \mathrm{m}^{2} / \mathrm{d}\right) \\
\text { Solar heat flux }\left(10^{2} \mathrm{~W} / \mathrm{m}^{2}\right) \\
\partial V / \partial t\left(10^{-4} \mathrm{Wm}^{2}\right)\end{array}$ & & & & \\
\hline
\end{tabular}
Discharge Along a 400-km Length and $20-\mathrm{km}$ Width of the Inner Shelf Off South Carolina, Georgia, and Florida

Depth $(H)$ available for mixing is assumed to be $10 \mathrm{~m}$, and $\partial V / \partial t \approx$ (H/2) $\rho^{\prime} N_{0}$ 
average maximum net solar radiation input for the southeastern U.S., which occurs in May [Odum, 1971]. We note that significantly more power appears to be required to mix freshwater discharge than to mix heat additions. Addition of solar heat during spring barely augments the potential energy of the water column, as compared to the potential energy induced by freshwater additions.

Tidal power is the principal process that is able to mix freshwater additions and can be expressed by

$$
\partial F / \partial t=\beta \rho_{0} C_{\mathrm{d}} U_{b}{ }^{3}
$$

where $F$ is amount of tidal energy available to increase the potential energy of the water column, $\beta$ is an efficiency factor taken by Fearnhead to be between 0.01 and $0.02, U_{b}$ is the rms value of the tidal current at the bottom and $C_{\mathrm{d}}$ is a drag coefficient which can vary from a 'conventional' value of $2 \times 10^{-3}$ to perhaps $6 \times 10^{-3}$ for shallow water with irregular bottom topography [Dronkers, 1964; Snyder et al., 1979]. We have measured tidal current amplitudes $1 \mathrm{~m}$ off bottom of about $0.15 \mathrm{~ms}^{-1} 10 \mathrm{~km}$ off the Georgia coast [Kundu et al., 1981]. For a sinusoidally varying current of amplitude $U_{b}, \partial F / \partial t=\beta\left(4 C_{\mathrm{d}} / 3 \pi\right) \rho U_{b}{ }^{3}$. Thus, $\partial F / \partial t \approx 0.3 \times$ $10^{-4} \mathrm{~W} / \mathrm{m}^{2}$ for $\beta=0.01, C_{\mathrm{d}}=2 \times 10^{-3} ; \partial F / \partial t \approx 0.6 \times 10^{-4}$ $\mathrm{W} / \mathrm{m}^{2}$ for $\beta=0.02, C_{\mathrm{d}}=2 \times 10^{-3} ;$ and $\partial F / \partial t \approx 1.8 \times 10^{-4}$ $\mathrm{W} / \mathrm{m}^{2}$ for $\beta=0.02, C_{\mathrm{d}}=6 \times 10^{-3}$. Comparing these values with $\partial V / \partial t$ in Table 2 , we conclude that tidal power is probably too weak to totally mix the line source of freshwater off Georgia and South Carolina in the inner $20 \mathrm{~km}$ except possibly during extremely low runoff conditions. We also conclude, based on the comparison at the bottom of Table 2 , that tidal power is probably sufficient to mix heat added by solar radiation.

We suspect that $U_{b}$ near the shoals adjacent to the many tidal inlets may approach as high as $0.5 \mathrm{~ms}^{-1}$, and even higher in the inlets themselves. Thus $\delta F / \delta t$ might range between $10^{-3}$ and $10^{-2} \mathrm{~W} / \mathrm{m}^{2}$ over localized areas. This would be sufficient to produce vertically homogeneous conditions. However, values of $U_{b}$ in excess of $0.15 \mathrm{~ms}^{-1}$ are not typical for the inner shelf as a whole, and we suspect that the conclusion reached above is valid.

Note that $\left(h / U_{b}{ }^{3}\right)>100$ for $h=15 \mathrm{~m}$ and $U_{b}=0.15 \mathrm{~ms}^{-1}$. By the criteria of Simpson and Hunter [1974], this suggests that there is insufficient mixing power to break down vertical stratification.

We recognize the uncertainty in these numbers caused by uncertainties in $C_{d}$ and $\beta$, to name a few. We are confident, however, that the estimates point favorably toward buoyancy flux caused by river discharge overcoming the tendency for tidal power to produce a well-mixed system. This results in an inclined frontal zone that stores a significant fraction of freshwater in the upper layer, where it is under the more immediate influence of wind stress. Bulk stratification parameters based on historical data [Atkinson et al., this issue] support the conclusion that the inner shelf in the study zone is stratified throughout the year. We explore the fate of the reduced salinity water by examining the horizontal currents versus depth through the frontal zone during typical spring conditions of April and May.

\section{Current Shear Through the Frontal Zone}

We hypothesize that the northeastward wind stress during spring of some years can be of sufficient strength to remove reduced-salinity water in the nearshore frontal zone. The various values of $\delta K_{f} f \delta t$ in Table 1 parameterize or reflect this process. In general, $\delta K_{f} / \delta t<0$ during the 'decay period' ending in July, signifying a loss of freshwater from the frontal zone.

We have examined profiles of horizontal currents during spring conditions when wind stress is usually positive (northeastward) alongshore. Tidal currents have been removed by averaging over an integral number of tidal cycles. During May 1978 (Figure 8 upper), the average wind stress for 25 hours was $0.4 \mathrm{dyne} / \mathrm{cm}^{2}$. Currents in the upper $5 \mathrm{~m}$ of the water column had an offshore component. As one approached bottom, the hodograph traced an anticlockwise path with some tendency for onshore flow near bottom. Differences between points $A$ and $B$ have been attributed to the complex coastal boundary in this region [Blanton, 1980]. During April 1981 (Figure 8 lower), a similar pattern occurred, even though the wind stress averaged over 50 hours was much weaker $\left(0.1 \mathrm{dyne} / \mathrm{cm}^{2}\right)$. Even so, upper-level currents had a distinct offshore component while lower-layer currents were onshore.

In both cases the currents transported the reduced-salinity water offshore, and mid-shelf water of higher salinity was advected onshore in the lower layer. This pattern was apparently in response to Ekman transport offshore caused by a combination of alongshore and offshore wind stress. With these data, we are unable to assess the relative

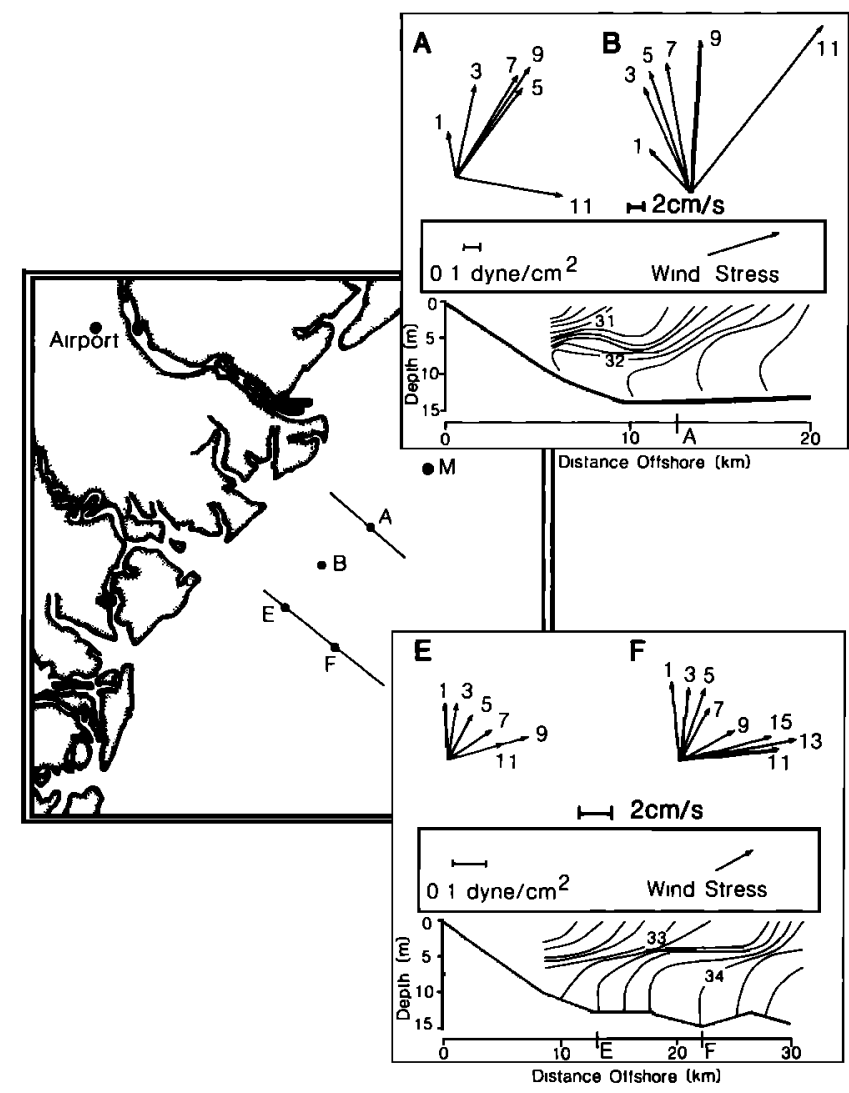

Fig. 8. Hodographs of horizontal currents through frontal zone at four locations (A, B, E, and F) during events when wind stress $(M)$ had a positive alongshore component: upper panel, May 9-11, 1978-averaged for two tidal cycles; lower panel, April 1-4, 1981averaged for four tidal cycles. Salinity cross sections are also shown. Numbers adjacent to velocity vectors denote distance $(\mathrm{m})$ above bottom. Note different stress and velocity scales when comparing upper and lower panels. 
importance of alongshore versus offshore wind components. Some of the low-salinity water could be advected alongshore and replaced by water of high salinity from farther south. We can show, however, that some spring seasons have sufficiently high alongshore wind stress to influence the magnitude of $-\delta K_{f} / \delta t$ (Table 1 ), thus representing a loss of freshwater from the study area. Moreover, Pietrafes $a$ and Janowitz [1979] have shown how upwelling favorable winds may decrease the horizontal density gradient with an accompanying loss of freshwater because of the upper-layer Eckman flux directed offshore.

\section{Relationship of Decreasing $K_{f}$ to Alongshore Wind Stress}

The wind regime from March to July (Figure 7) was highly variable, with extreme variability during years 1957 and 1961. During 1957, the alongshore impulse curve sloped upward from January to April, when it reached a value of 2 $\mathrm{kg}^{-1} \mathrm{~m}^{-1} \mathrm{~s}^{-1}$. From April to July the curve was almost flat and, in fact, sloped slightly downward, representing an average southeastward wind stress. The offshore component during this period had a definite negative slope, indicating onshore wind stress during this period. The changes in $K_{f}$ during this year are different than expected (Figure 6). While discharge peaked in April, $K_{f}$ continued to increase into June. Apparently, weak alongshore wind stress was ineffective in transporting reduced-salinity water. More significantly, there was a relatively strong onshore stress that may have confined reduced-salinity water against the coast. Thus, $K_{f}$ apparently increased because the discharge was effectively confined to the inner shelf zone. The 'decay period' lasted only 1 month (Table 1), during which time there was an average northeastward wind stress of $+0.07 \mathrm{dyne} / \mathrm{cm}^{2}$. The stress vector still had an onshore component during the 1month period.

During 1961, conditions were more typical of the average. There was a long period of northeastward wind stress lasting until August (Figure 7). The decay period lasted 3 months (Table 1), during which there was a weakened onshore component of stress compared to that in 1957. Winds were measured at Savannah Airport, $35 \mathrm{~km}$ inland, and weak 'onshore/offshore' components may not be significant. However, the relatively strong onshore stress in 1957 was undoubtedly real, even when allowing for a reasonable uncertainty in coordinate orientation.

Alongshore wind stress averaged over the decay period is undoubtedly one of the more important processes that lowers freshwater content on the inner shelf. We plotted $\tau_{y}$ versus $K_{f}^{-1}\left(\delta K_{f} / \delta t\right)$ in Table 1 (Figure 9). Questionable data in 1963 resulted from assuming that missing bottom salinity data could be estimated by a linear change from $34 \times 10^{-3}$ in April to $35 \times 10^{-3}$ in August. The plot suggests that there is a more or less constant decay rate at low levels of alongshore wind stress. When levels become greater than $0.1 \mathrm{dyne} / \mathrm{cm}^{2}$, there seems to be a clear relationship between the level of alongshore wind stress and decay rate. A plot (not shown) of $\tau_{x}$ versus $K_{f}^{-1}\left(\delta K_{f} / \delta t\right)$ produced no clear relationship over the range of $\tau_{x}$ in Table 1 . We suggest that Ekman transport offshore would occur at the higher wind stress values as depicted in Figure 8 for near-surface flow. While the depthaveraged current generated by wind stress appears close to alongshore, the internal pressure gradient in the frontal zone causes a cyclonic spiral with depth so that high wind stress generates surface currents to the right of the stress vector

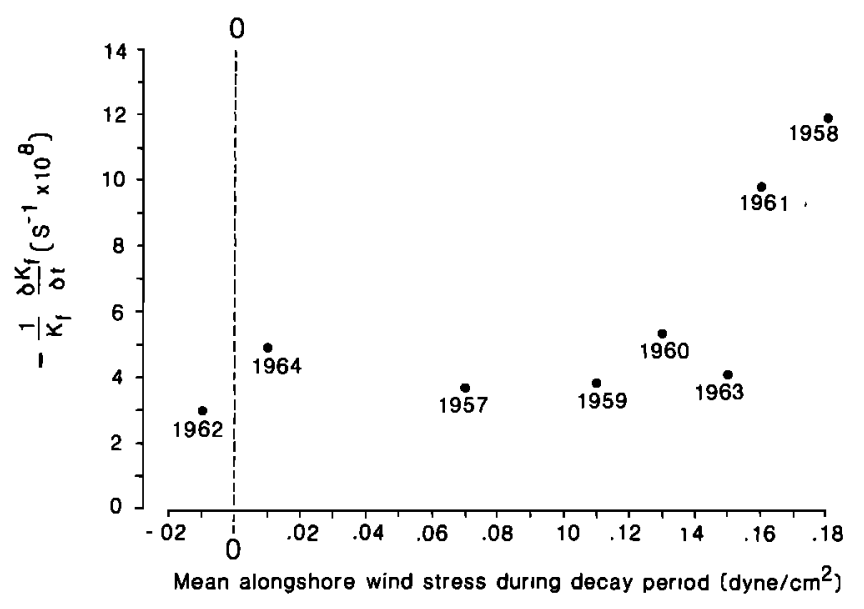

Fig. 9. Plot of alongshore wind stress averaged over the period that $K_{f}^{-i}\left(\delta K_{f} / \delta t\right)<0$. Data in 1963 are questionable. (See text for details.)

and induces a high loss of low-salinity water in the upper layer. Underneath there is compensating onshore flow of higher-salinity water.

Below about $0.1 \mathrm{dyne} / \mathrm{cm}^{2}$, the data suggest that freshwater removal is more or less insensitive to alongshore wind stress. Onshore wind stress usually prevails during the decay period and may help to confine low-salinity water near the coast. This would result in a lower decay rate unless levels of alongshore wind stress are significantly high enough to set up a circulation pattern similar to that depicted in Figure 8.

We offer some additional comments on Figure 9. There seems to be a 'threshold' rate of loss of freshwater on the inner shelf $\left(K_{f}^{-1}\left[\delta K_{f} / \delta t\right] \approx-4 \times 10^{-8} \mathrm{~s}^{-1}\right)$. This would suggest a source of mixing energy approximately constant over time. The most likely candidate is energy from tidal currents. Blanton [1980] has shown that there are large alongshore gradients in tidal currents on the inner shelf near the Savannah River. This represents an effective mixing process that would dilute pools of riverine (low-salinity) water with the ambient shelf water after a few tidal cycles. While this is quite speculative, we suggest that tidal mixing processes produce a rather constant dilution of low-salinity water during the decay period, and it can be significantly augmented during years when the seasonal average of alongshore stress is sufficiently high.

\section{Conclusions}

The nearshore frontal zone may be described as a storage zone for freshwater discharge that occurs along $400 \mathrm{~km}$ of the SAB. Blanton [1981] described the balance of momentum commonly observed in autumn when southward wind stress maintains a steeply inclined frontal zone with vertically sheared southward flow. During spring, however, when freshwater discharge is maximum, wind stress is commonly northward, and surface currents apparently overcome the tendency for southward flow. The inclined frontal zone is less steep and may become horizontal at times [Blanton, 1981]. Based on the few cases cited here, surface currents are northward and have a significant offshore component near surface and an onshore component near bottom (Figure 7). Under these conditions the frontal zone probably stores the freshwater mixture less effectively.

The storage process has been parameterized by the change 
in time of the freshwater content $\left(\delta K_{f} / \delta t\right)$ normalized by the average content $\bar{K}_{f}$. When $\delta K_{f} / \delta t>0$, storage is taking place. This can occur even in spring (see Figure $6 a$, for example). More commonly, $\delta K_{f} / \delta t<0$ during spring, and its magnitude is roughly proportional to the magnitude of alongshore wind stress (Figure 9).

Spring meteorological conditions may accelerate the removal of reduced-salinity water from the nearshore zone. The buoyancy flux of freshwater discharge is too strong for tidal mixing to destroy stratification on the inner shelf. Presumably, trace elements that do not precipitate nearshore or are resuspended from bottom when bottom currents become strong enough are also removed with the reducedsalinity water. Thus strong northward wind stress coupled with strong buoyancy flux may tilt the frontal zone horizontally and allow the distributed freshwater source to spill offshore. In April 1980, low-salinity water was confined to a two-layer system stretching all the way to the Gulf Stream (L. P. Atkinson, unpublished manuscript, 1982). This situation could have evolved as a result of extremely high buoyancy flux associated with high freshwater discharge (Figure 2) and a strong cold front that induced gale force winds to the northeast 1 day before the two-layer system was observed (J. O. Blanton, unpublished data, 1982).

If low-salinity water is ejected from the nearshore zone during typical spring conditions, we would expect to find evidence of reduced-salinity water offshore during spring. In April and May, historical data indicate that reduced-salinity water is found off the South Carolina coast out to the $40-\mathrm{m}$ isobath [Atkinson et al., this issue]. Thus, seasonal processes occurring in late spring cause the inner shelf zone to eject reduced-salinity water. During the light winds of summer and during fall, when wind stress is southward, the freshwater discharge is effectively stored within the frontal zone, only to be ejected again where wind stress reverses, and the high buoyancy flux in spring tends to tilt the inner-shelf front to a more horizontal position.

Acknowledgments. We are grateful for the assistance of $\mathrm{J}$. Singer, P. O'Malley, W. Chandler, L. Lamhut, and B. Blanton for obtaining and analyzing much of the data utilized in this paper. S. McIntosh and A. Boyette drafted the illustrations, and L. Land typed the manuscript. T. N. Lee offered many valuable suggestions in the preparation of this paper. This work is a result of research sponsored by the U.S. Department of Energy under contracts DEAS09-76EV00889, DE-AS09-80EV10331, and DE-AS09-76EV00901; and by the Georgia Sea Grant College Program, Office of Sea Grant, NOAA (04-7-158-44126).

\section{REFERENCES}

Atkinson, L. P., J. O. Blanton, and E. Haines, Shelf flushing rates based on the distribution of salinity and freshwater in the Georgia Bight, Estuarine Coastal Mar. Sci., 7, 465-472, 1978.
Atkinson, L. P., T. N. Lee, J. O. Blanton, and W. S. Chandler, Climatology of the southeastern United States continental shelf waters, J. Geophys. Res., this issue.

Blanton, J. O., The transport of freshwater off a multi-inlet coastline, in Estuarine and Wetland Processes, edited by P. Hamilton and K. B. MacDonald, pp. 49-64, Plenum, New York, 1980.

Blanton, J. O., Ocean currents along a nearshore frontal zone on the continental shelf of the southeastern U.S., J. Phys. Oceanogr., $11,1627-1637,1981$.

Blanton, J. O., and L. P. Atkinson, Physical transfer processes between Georgia tidal inlets and nearshore waters, in Estuarine Interactions, edited by M. Wiley, pp. 514-532, Academic, New York, 1978.

Chase, J., Oceanographic observations, 1961, Data Rep. 1, 176 pp., U.S. Fish Wildlife Serv., Wash., D. C., 1964.

Chase, J., Oceanographic observations, 1962, Data Rep. 9, 181 pp., U.S. Fish Wildlife Serv., Wash., D. C., 1965.

Chase, J., Oceanographic observations, 1963, Data Rep. 10, 173 pp., U.S. Fish Wildlife Serv., Wash., D. C., 1966.

Chase, J., Oceanographic observations, 1964, Data Rep. 18, 177 pp., U.S. Fish Wildlife Serv., Wash., D. C., 1967.

Day, C. G., Oceanographic observations, 1957, East Coast of the United States, Spec. Sci. Rep.-Fish. 282, 123 pp., U.S. Fish Wildlife Serv., Wash., D. C., 1959a.

Day, C. G., Oceanographic observations, 1958, East Coast of the United States, Spec. Sci. Rep.-Fish. 318, 119 pp., U.S. Fish Wildlife Serv., Wash., D. C., $1959 b$.

Day, C. G., Oceanographic observations, 1959, East Coast of the United States, Spec. Sci. Rep.-Fish. 359, 114 pp., U.S. Fish Wildlife Serv., Wash., D. C., 1960.

Day, C. G., Oceanographic observations, 1960, East Coast of the United States, Spec. Sci. Rep.-Fish. 406, 59 pp., U.S. Fish Wildlife Serv., Wash., D. C., 1963.

Dronkers, J. J., Tidal Computations in Rivers and Coastal Waters, 518 pp., North-Holland, Amsterdam, 1964.

Fearnhead, P. G., On the formation of fronts by tidal mixing around the British Isles, Deep-Sea Res., 22, 311-321, 1975.

Kundu, P. K., J. O. Blanton, and M. M. Janopaul, Analysis of current observations on the Georgia shelf, J. Phys. Oceanogr., II, 1139-1149, 1981

Odum, E. P., Fundamentals of Ecology, 574 pp., W. B. Saunders Co., Philadelphia, Pa., 1971.

Phillips, O. M., The Dynamics of Upper Ocean, 261 pp., Cambridge University Press, New York, 1966.

Pietrafesa, L. J., and G. S. Janowitz, On the effects of buoyancy flux on continental shelf circulation, J. Phys. Oceanogr., 9, 911918, 1979.

Simpson, J. H., and J. R. Hunter, Fronts in the Irish Sea, Nature, 250, 404-406, 1974.

Snyder, R. L., M. Sidjabat, and T. H. Filloux, A study of tides, setup and bottom friction in a shallow semi-enclosed basin, Part 2 , Tidal model and comparison with data, J. Phys. Oceanogr., 9, 170-188, 1979.

Weber, A. H., and J. O. Blanton, Monthly mean wind fields for the South Atlantic Bight, J. Phys. Oceanogr., IO(8), 1256-1263, 1980.

(Received April 23, 1982; revised September 7, 1982; accepted September 8, 1982.) 